\title{
Effect of Oral Nutritional Supplementation on National Institute of Health Stroke Scale in Acute Ischemic Stroke
}

\author{
Chairil Amin Batubara*, Listra Isabela Barus, Aida Fithrie \\ Department of Neurology, Faculty of Medicine, Universitas Sumatera Utara, Adam Malik General Hospital, Medan, Indonesia
}

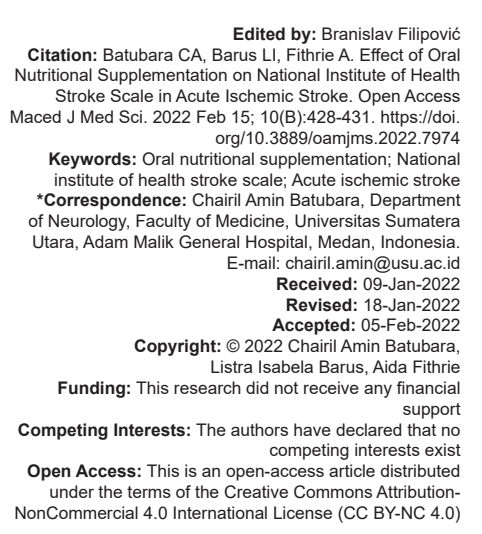

Introduction

Stroke management continues to develop. Providing and monitoring a proper and optimal nutritional assessment has become an important issue [1]. Approximately, $6-31 \%$ of nutritional deficits are present before the stroke and worsen during hospitalization. A previous research has shown that post-ischemic calorie-protein nutritional deficiency is a risk factor for poor clinical outcomes. Patients consume only $67 \%$ of their daily recommended intake during the first-week post-stroke and up to $85 \%$ of their calorie requirements during the first few weeks post-stroke [2], [3].

One intervention to overcome stroke patients' nutritional problems is giving oral nutritional supplementation (ONS) [4]. Oral nutritional supplementation is a supplement that contains macronutrients and micronutrients that are widely used by individuals who cannot meet their nutritional needs only through an oral diet. Oral nutritional supplementation may be stated in stroke patients who can consume food orally but cannot meet sufficient quantities to meet nutritional requirements or are in a state of nutritional deficit [4], [5].
Several studies reported the benefit of ONS supporting daily calorie and nutritional intake, which was characterized by positive effects on functional aspects (e.g., increased motor strength), nutritional status (e.g., weight gain, achievement of daily calorie and protein targets), and clinical (e.g., reduced incidence of pressure ulcers, mortality, and shortened hospital stay) [6], [7]. Macronutrients such as protein in ONS can help reactivate neural protein synthesis, thereby increasing neuronal energy and neurotransmitter function [6]. Micronutrients such as vitamins $C$ and $E$ act as antioxidants [3], [8]. Zinc, choline, and vitamin B play a role in neurotransmitter synthesis [9], [10], [11]. Potassium and magnesium increase the repair of cellular energy metabolism, while omega-3 increases cerebral angiogenesis, which ultimately improves the functional outcome of ischemic stroke patients [12], [13].

In contrast to the results of previous studies that supported the positive effects of oral nutritional supplementation, the largest clinical trial to date examining the effect of oral nutritional supplementation on stroke patients, The Feed or Ordinary Diet (FOOD) trial, stated that no benefit was found from supplementation. This study reported no significant differences in mortality rates and outcomes assessed by mRS (modified Rankin 
Scale) scores between the two groups [14]. Based on the description above, this study aimed to evaluate the effect of oral nutritional supplementation on the National Institute of Health Stroke Scale (NIHSS) score in patients with acute ischemic stroke.

\section{Methods}

Twenty-eight patients with acute ischemic stroke were randomly included in a randomized, controlled clinical trial. The participants were selected from patients referred to Adam Malik General Hospital, Medan, Indonesia, from March to October 2021. The inclusion criteria in this study were patients who had aged more than 18 years old, who was diagnosed with acute ischemic stroke within 7 days after onset, confirmed by head CT-scan, who had the NIHSS scores $<20$. On the other hand, patients who had one or more than one of the following features were excluded from this study: Patients with malignancy, sepsis, impaired liver function, and kidney failure.

Patients were assigned into intervention ( $n=14$ ) or control $(n=14)$ groups randomly using a random number table. Patients in the control group received a normal hospital diet. However, the intervention group participants, in addition to normal hospital diet, also received oral nutritional supplementation, commercially available in Indonesia (Table 1), in the form of milk powder for 7 days of hospitalization in the amount of 1 serving per day as a complementary food given between lunch and dinner. The method of presenting oral nutritional supplementation is to prepare $200 \mathrm{~mL}$ of warm boiled water with a temperature of $\pm 70^{\circ} \mathrm{C}$, then add 4 measuring

Table 1: Nutrition fact of oral nutritional supplementation

\begin{tabular}{ll}
\hline Nutrition fact & Oral nutritional supplementation (one serving per day) \\
\hline Energy & $290 \mathrm{kcal}$ \\
Protein & $15 \mathrm{~g}$ \\
Fat & $5 \mathrm{~g}$ \\
Carbohydrate & $44 \mathrm{~g}$ \\
Sodium & $65 \mathrm{mg}$ \\
Potassium & $710 \mathrm{mg}$ \\
Vitamin A & $30 \%$ daily value \\
Vitamin C & $80 \%$ daily value \\
Vitamin D3 & $8 \%$ daily value \\
Vitamin E & $25 \%$ daily value \\
Vitamin B1 & $50 \%$ daily value \\
Vitamin B2 & $25 \%$ daily value \\
Niacin & $25 \%$ daily value \\
Vitamin B6 & $30 \%$ daily value \\
Vitamin B12 & $15 \%$ daily value \\
Folic acid & $25 \%$ daily value \\
Pantothenic acid & $15 \%$ daily value \\
Calcium & $30 \%$ daily value \\
Iron & $8 \%$ daily value \\
Phosphor & $30 \%$ daily value \\
Magnesium & $25 \%$ daily value \\
Zinc & $45 \%$ daily value \\
lodine & $15 \%$ daily value \\
Selenium & $35 \%$ daily value \\
Triglyceride medium & $1.1 \mathrm{~g}$ \\
Omega 3 & $0.2 \mathrm{~g}$ \\
Omega 6 & $1 \mathrm{~g}$ \\
Inulin & $3 \mathrm{~g}$ \\
Choline & 128 mg \\
\hline
\end{tabular}

spoons (69 g), stir until homogeneously mixed. Oral nutritional supplementation is not recommended using hot water, because it can damage the protein. Oral nutritional supplementation reconstituted within $5 \mathrm{~h}$ should be taken.

The NIHSS scores were evaluated on day 1 and day 8 from the intervention. NIHSS is a systematic method that provides a quantitative measure of stroke-induced neurological damage and is generally designed for patients with acute stroke. The scale contains 15 items assessing the acute stroke effect on consciousness, language, eye movements, motor force, ataxia, and sensorium level. Each item is scored either on a 3 or 5 point scale, zero indicates the normal state, and the upper limit is 42 .

According to the stroke management guidelines, all participants received the same treatment during hospitalization. The study protocol was approved by The Committee for Medical and Health Research Ethics, Faculty of Medicine, Universitas Sumatera Utara, Medan, Indonesia with registration number 415/ KEP/USU/2021.

\section{Statistical analysis}

The IBM SPSS $®$ software was utilized to perform all statistical analyses. Data were expressed as mean \pm standard deviation (SD), frequency, and percentage. In addition, unpaired t-test and MannWhitney $U$ test were utilized to compare quantitative variables. Moreover, the paired t-test or Wilcoxon signed-rank test was also used to examine intra-group changes before and after the intervention. $p$ values $\leq$ 0.05 were considered statistically significant.

\section{Results}

Finally, 14 ischemic stroke patients in the intervention group and 14 ischemic stroke patients in the control group were included in the present study, concerning the inclusion and exclusion criteria, consisting of $7(50.00 \%)$ males and 7 (50.00\%) females in the control dan intervention group, respectively. The total participant's mean ages were 58.89 years old. The baseline characteristics of the patients in the study group are indicated in Table 2.

Table 2: Baseline characteristics

\begin{tabular}{llll}
\hline Variables & Total Subject & Group \\
\cline { 3 - 4 } & & Control $(\mathrm{n}=14)$ & Intervention $(\mathrm{n}=14)$ \\
\hline Age (years) & $58.89 \pm 16.89$ & $63.00 \pm 18.66$ & $54.79 \pm 14.42$ \\
Sex & & $7(50.0 \%)$ & $7(50.0 \%)$ \\
$\quad$ Male & $14(50.0 \%)$ & $7(50.0 \%)$ & $7(50.0 \%)$ \\
Female & $14(50.0 \%)$ & $-2.57 \pm 1.98$ & $-2.28 \pm 1.63$ \\
$\Delta$ NIHSS & $-2.42 \pm 1.79$ & &
\end{tabular}

Data are expressed as mean \pm standard deviation, frequency, and percentage. $\Delta$ means the difference between day 1 dan day 8 . 
Paired t-test was conducted to assess the comparison of the NIHSS scores at the beginning and the end of the study in each group (Table 3). Data analyses in the control group demonstrated a significant change of the NIHSS scores $(p<0.001)$ between day 1 and day 8. A significant reduction of the NIHSS scores was also found in the intervention group $(p<0.001)$.

Table 3: Comparison of the NIHSS at the beginning and the end of the study in patients in the control group and intervention group

\begin{tabular}{llll}
\hline NIHSS changes & \multicolumn{2}{l}{ Evaluation time } & p-value \\
\cline { 2 - 3 } & Day 1 & Day 8 & \\
\hline Control group & $8.57 \pm 2.53$ & $6.00 \pm 2.00$ & $<0.001$ \\
Intervention group & $9.21 \pm 3.64$ & $6.93 \pm 3.10$ & $<0.001$ \\
\hline
\end{tabular}

Intergroup comparison using unpaired t-test demonstrated that the NIHSS indicated no significant change $(p=0.682)$ between the control and intervention groups during the investigation (Table 4).

Table 4: Comparison of the NIHSS changes between control and intervention groups during the study

\begin{tabular}{llll}
\hline Variable & Group & p-value \\
\cline { 2 - 3 } & Control & Intervention & \\
\hline$\Delta$ NIHSS & $-2.57 \pm 1.98$ & $-2.28 \pm 1.63$ & 0.682 \\
\hline Unpaired t-test. $\Delta$ means the difference between day 1 dan day 8. &
\end{tabular}

\section{Discussion}

Patients consume $67 \%$ of their daily recommended intake during the first-week post-stroke and up to $85 \%$ of their calorie requirements during the first few weeks post-stroke. Individuals with stroke may be particularly vulnerable to calorie-protein malnutrition due to various factors that affect their ability or willingness to self-feed. Cognitive changes to attention, concentration, and memory may affect eating behaviors post-stroke. Self-feeding ability may be attenuated by upper extremity paresis/paralysis, visuospatialperceptual deficits, left-right disorientation, hemispatial neglect, apraxia, and agnosia. Sensory disturbances and mood disorders, such as depression, may affect the desire to self-feed [2].

Several other studies have shown that adequate nutritional support for stroke patients can accelerate the recovery of neurological dysfunction, prevent infection, and is expected to reduce the length of hospital stay. A study conducted by Sato et al. reported that stroke patients who received higher energy intake ( $23.5 \mathrm{kcal} / \mathrm{kg} /$ day) during 7 days of hospitalization had higher activity daily living (ADL) at discharge and more patients discharged home than those with lower energy intake (12.4 kcal/kg/day) with $p<0.001$ [15]. Research conducted by Li et al. reported that oral nutritional supplementation significantly increased energy intake $(p=0.02)$ and increased appetite $(p<0.001)$, both in hospitalized patients and in the community, without reducing the amount of intake from the meal [16]. Patient compliance with the use of oral nutritional supplementation was also reported to be quite high (mean 78\%) compared to other methods of nutritional support [17], [18].

Beyond the positive effects of oral nutritional supplementation, this study results reported no significant difference in the NIHSS scores between the control and intervention groups $(p=0.682)$. Although there was an improvement in stroke severity as indicated by a decrease in the NIHSS score on day-8 in both study groups, an unpaired t-test was performed to compare the delta NIHSS scores between the two groups was no significant difference.

These results are relevant to the study conducted by Hashemilar et al., which reported no difference in stroke severity with NIHSS scores between the intervention group $(-1.47 \pm 1.87)$ and the control group $(-2.05 \pm 1.92)$ with $p=0.34$ [7]. A similar result was also reported in the largest clinical trial to date, The Feed or Ordinary Diet (FOOD) trial, which examined the benefits of routine administration of oral nutritional supplementation in hospitalized stroke patients. This clinical trial involving 4023 stroke patients from 125 hospitals in 15 countries reported no significant difference in mortality rates and outcomes assessed by $\mathrm{mRS}$ scores between the two groups [2], [14].

In contrast, a study conducted by Rabadi et al. found that intensive nutritional supplementation using readily available commercial preparations improves motor recovery in previously undernourished patients receiving intensive inpatient rehabilitation after stroke [19]. A similar result was found in the study of Aquilani et al. which reported a significant difference in NIHSS scores between the intervention group and the control group $(-4.4 \pm 1.5$ vs. $-3 \pm 1.4) ; p<0.01$. The findings of this study differ from those of Aquilani et al. and Rabadi et al. because this study differs in several important aspects. First, patients in our study were randomized within 7 days after onset, rather than 14-18 days poststroke in the other study. Second, prior studies were in a rehabilitation setting, while our patient population was in an acute hospital setting. Third, it could be due to the different duration and products of ONS used in these studies [6]. Our study had several limitations including small sample size, lack of placebo, and lack of blinding. Therefore, further studies with larger sample sizes are necessary to evaluate the effect of ONS. However, our inability to measure the benefit from oral nutritional supplementation could have been because normal hospital diets in our center fully met the nutritional needs of the patients.

\section{Conclusion}

The effect of oral nutritional supplementation significantly reduced the NIHSS scores in acute 
ischemic stroke, but there was no significant difference compared to the normal hospital diet. In conclusion, this study's results do not support the use of routine oral nutritional supplementation in acute ischemic stroke patients.

\section{References}

1. Misbach J, Rasyid A, Bustamin M, Arupah U. Nutrition care process. In: Soertidewi L, Jannis J, editors. Stroke: Aspek Diagnostik, Patofisiologi, Manajemen. Jakarta: Badan Penerbit FK UI; 2011. p. 357-89.

2. Foley $\mathrm{N}$, Teasell $\mathrm{R}$, Richardson $\mathrm{M}$, Wiener J, Finestone $\mathrm{H}$. Nutritional intervention following stroke. In: Evidenced-Based Review of Stroke Rehabilitation; 2018. p. 1-42. Available from: https://www.ebrsr.com. [Last accesed on 2021 Mar 20].

3. Lieber AC, Hong E, Putrino D, Nistal DA, Pan JS, Kellner CP. Nutrition, energy expenditure, dysphagia, and self-efficacy in stroke rehabilitation: A review of the literature. Brain Sci. 2018;8(12):218. https://doi.org/10.3390/brainsci8120218 PMid:30544517

4. Jensen GL. Oral nutritional supplementation. Am J Manag Care. 2013;19(2):119-20.

PMid:23448108

5. Arsava EM, Aydoğdu I, Güngör L, Işıkay CT, Yaka E. Nutritional approach and treatment in patients with stroke, an expert opinion for Turkey. Turk Norol Derg. 2018;24(3):226-42. https:// doi.org/10.4274/tnd.92603

6. Aquilani $R$, Scocchi $M$, ladarola $P$, Franciscone $P$, Verri $M$, Boschi $\mathrm{F}$, et al. Protein supplementation may enhance the spontaneous recovery of neurological alterations in patients with ischaemic stroke. Clin Rehabil. 2008;22(12):1042-50. https://doi.org/10.1177/0269215508094244

PMid: 19052243

7. Hashemilar M, Khalili M, Rezaeimanesh N, AHokmabadi ES, Rasulzade S, Shamshirgaran SM, et al. Effect of whey protein supplementation on inflammatory and antioxidant markers, and clinical prognosis in acute ischemic stroke (TNS Trial): A randomized, double blind, controlled, clinical trial. Adv Pharm Bull. 2020;10(1):135-40. https://doi.org/10.15171/jcvtr.2015.24 PMid:32002373

8. Harrison F, May JM. Vitamin $C$ function in the brain: Vital role of ascorbate transporter (SVCT2). Free Radic Biol Med. 2010;46(6):719-30. https://doi.org/10.1016/j. freeradbiomed.2008.12.018

PMid:19162177
9. Gower-Winter SD, Levenson CW. Zinc in the central nervous system: From molecules to behavior. Biofactors. 2012;38(3):18693. https://doi.org/10.1002/biof.1012

PMid:22473811

10. Biswas S, Giri S. Importance of choline as essential nutrient and its role in prevention of various toxicities. Prague Med Rep. 2015;116(1):5-15. https://doi. org/10.14712/23362936.2015.40 PMid:25923965

11. Kennedy DO. B vitamins and the brain: Mechanisms, dose and efficacy-a review. Nutrients. 2016;8(2):68. https://doi. org/10.3390/nu8020068

PMid:26828517

12. Hunt BD, Cappuccio FP. Potassium intake and stroke risk: A review of the evidence and practical considerations for achieving a minimum target. Stroke. 2014;45(5):1519-22. https://doi.org/10.1161/STROKEAHA.113.004282 PMid:24699056

13. Wang J, Shi Y, Zhang L, Zhang F, Hu X, Zhang W, et al. Omega-3 polyunsaturated fatty acids enhance cerebral angiogenesis and provide long-term protection after stroke. Neurobiol Dis. 2014;68:91-103. https://doi.org/10.1016/j.nbd.2014.04.014 PMid:24794156

14. Dennis M. Routine oral nutritional supplementation for stroke patients in hospital (FOOD): A multicentre randomised controlled trial. Lancet. 2005;365(9461):755-63. https://doi.org/10.1016/ S0140-6736(05)70998-3

PMid:15733716

15. Sato $Y$, Yoshimura $Y, A$ Abe T. Nutrition in the first week after stroke is associated with discharge to home. Nutrients. 2021;13(3):1-9. https://doi.org/10.3390/nu13030943 PMid:33804072

16. Li M, Zhao S, Wu S, Yang $\mathrm{X}$, Feng $\mathrm{H}$. Effectiveness of oral nutritional supplements on older people with anorexia: A systematic review and meta-analysis of randomized controlled trials. Nutrients. 2021;13(3):1-24. https://doi.org/10.3390/ nu13030835 PMid:33802580

17. Hubbard GP, Elia M, Holdoway A, Stratton RJ. A systematic review of compliance to oral nutritional supplements. Clin Nutr. 2012;31(3):293-312. https://doi.org/10.1016/j.clnu.2011.11.020 PMid:22257636

18. Page F. Oral Nutritional Supplements to Tackle Malnutrition. Brussels, Belgium: Medical Nutrition International Industry; 2012. p. 82-106. Available from: https://www. medicalnutritionindustry.com

19. Rabadi MH, Coar PL, Lukin M, Lesser M, Blass JP. Intensive nutritional supplements can improve outcomes in stroke rehabilitation. Neurology. 2008;71(23):1856-61. https://doi. org/10.1212/01.wnl.0000327092.39422.3c 